\title{
PLANNING OF THE EXPERIMENTATION TO EXAM DEVIATIONS IN PARAMETERS OF MACHINE/MECHANICAL TAPS
}

\section{Detelina Angelova, Stefan Kartunov}

Summary: This article is studying the market portfolio analysis of GWG in Gabrovo, Bulgaria. We present the work drawings of taps M4, M6, M8, M10 and their variations, the tolerances of their dimensions We have planned the test of number ofexperimentations and the factors to be examined.

Keywords: Experimentation, machine taps, dimensions, tolerances.

\section{INTRODUCTION}

The factory for threading instruments in Gabrovo - GWG is the biggest producer of cutting instruments in Bulgaria. It,s production is of high quality: tools for orifices and chamfers, for cutting internal and external threads, for milling and gear-cutting as well as for special needs.

TAPS: Hand and Machine taps-as per DIN and ISO, with straight flutes and with chamfer - for through holes and spiral flutes - for blind holes. Short machine taps, Machine nut taps, Flute less taps, Taps for wire-threadinserts, Combined taps.

Other countries are also producing thread cutting instruments: Great Britain, Germany, Italy, Russia, Turkey, France, Check Republic etc. There are differences in quality, prices of instruments, materials, machines, technologies, processing etc They are mainly used for manual cutting of threads. Material for made is fast-cutting steal with sanded profile of the thread.

For tabs with step to $3 \mathrm{~mm}$ are manufactured two element sets and for tabs with steps over $3 \mathrm{~mm}$ are manufactured three elements sets.

\section{- Machine Taps}

Their main purpose is for machine cutting of threads passage and hollow holes. According of the hole we differ three types of taps:

- implementation A, for passage holes with long cutting part;

- implementation B, for passage holes with sloped cutting part; implementation $\mathrm{C}$, for hollow holes with short cutting part.
Portfolio analysis of the market position of the company is shown in the table below.

\begin{tabular}{c|c}
\multicolumn{2}{c}{ Fig. 1: Portfolioanalyses } \\
$\begin{array}{c}\text { Italy } \\
\text { High Quality } \\
\text { France }\end{array}$ & $\begin{array}{c}\text { Tops } \\
\text { Germany Gritain }\end{array}$ \\
\hline $\begin{array}{c}\text { Russia } \\
\text { Low quality } \\
\text { Turkey, China }\end{array}$ & $\begin{array}{c}\text { Check Republic } \\
\text { Middle quality } \\
\text { Gabrovo - Bulgaria }\end{array}$
\end{tabular}

The aim of this article is to plan the experiment of mistake examination in the production of instruments.

Taps are used for cutting or calibration if internal threads.

\subsection{Types of taps and their purposes}

- Hand Taps - set

- Machine taps with screw canals.

We differ these types of taps:

- Machine tabs type $\mathrm{N}$ - with angle of screw line $\mathrm{w}=15^{\circ}$, which are:

-implementation $\mathrm{A}$, for passage holes with left slope of screw line -implementation $\mathrm{C}$, for hollow holes with right slope of screw line

- machine tabs type $\mathrm{W}$ - with angle of screw line $\mathrm{w}=35^{\circ}$, which are:

-implementation $\mathrm{D}$, for passage holes with left slope of screw line

-implementation $\mathrm{C}$, for hollow holes with right slope of screw line

Nut taps.

Their use is for serial production for cutting threads in nuts. Taps with rights tails are used for cutting threads in nuts with help of drills and automats. 
Proc. of the Second Intl. Conf. on Advances in Mechanical and Automation Engineering - MAE 2015

Copyright (C) Institute of Research Engineers and Doctors, USA .All rights reserved.

ISBN: 978-1-63248-045-3 doi: 10.15224/ 978-1-63248-045-3-130

Tapered taps.

Their use is for cutting tapered threads, on hand or machine, wherein cutting is made with all notch.

Taps for trapezoidal threads.

Their use is for trapezoidal threads in nuts.

Purpuse of current article is to be planed the experiment for study errors of manufacturing tools.

\section{EXPOSITION}

\section{TECHNICAL REQUIREMENTS}

Object of this experimentation are machine taps M4 M6 M8 M10. Table drawing of taps is presented. Their dimensions are the incoming parameters of the experimentation.

Options for production of Taps M4, M6, M8, M10 are also presented.

Fig. 2: Table drawing of taps: M4; M6; M8; M10

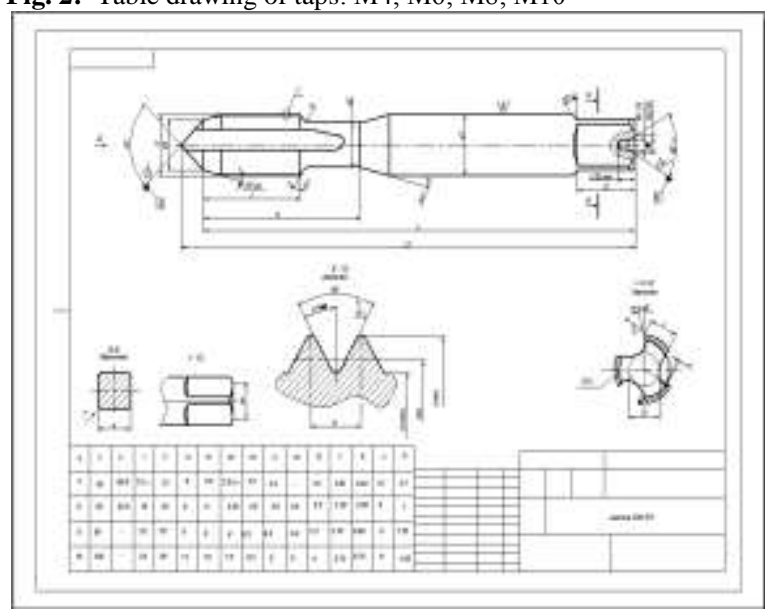

Legend: L total length of the tap, $\mathrm{mm}$; 1 - length of the working part, $\mathrm{mm}$; 12 - length of square, $\mathrm{mm}$;

$\mathrm{d} 2$ - diameter of curvy, $\mathrm{mm}$;

$\mathrm{d}$ - external diameter of the thread, $\mu \mathrm{m}$;

$\mathrm{d}$ - middle diameter of the thread, $\mu \mathrm{m}$;

$\mathrm{d}$ - internal diameter of the thread, $\mu \mathrm{m}$; $\mathrm{a} \square$ - square, mm; P - pitch of the thread, mm; D - diameter of the core; $\mathrm{d} 3$ - frontal diameter, $\mathrm{mm}$; $\mathrm{f}$ - width of the nib, mm; d1 - diameter of the tail.

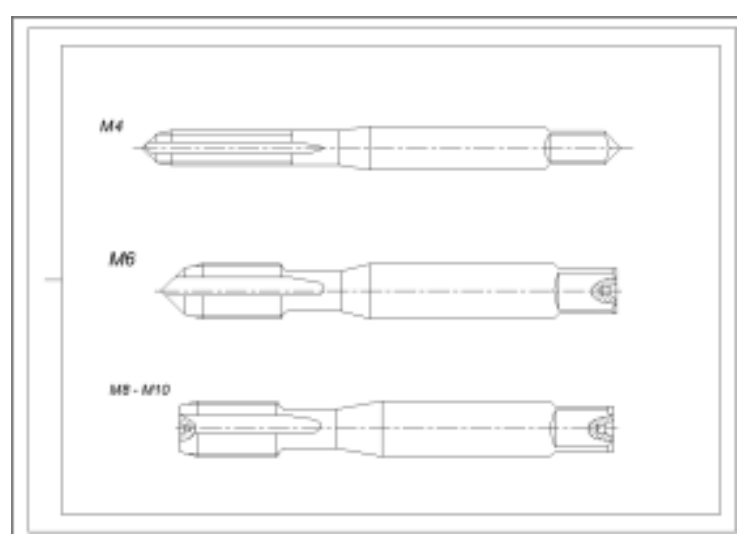

Fig.3. Variations of machine taps

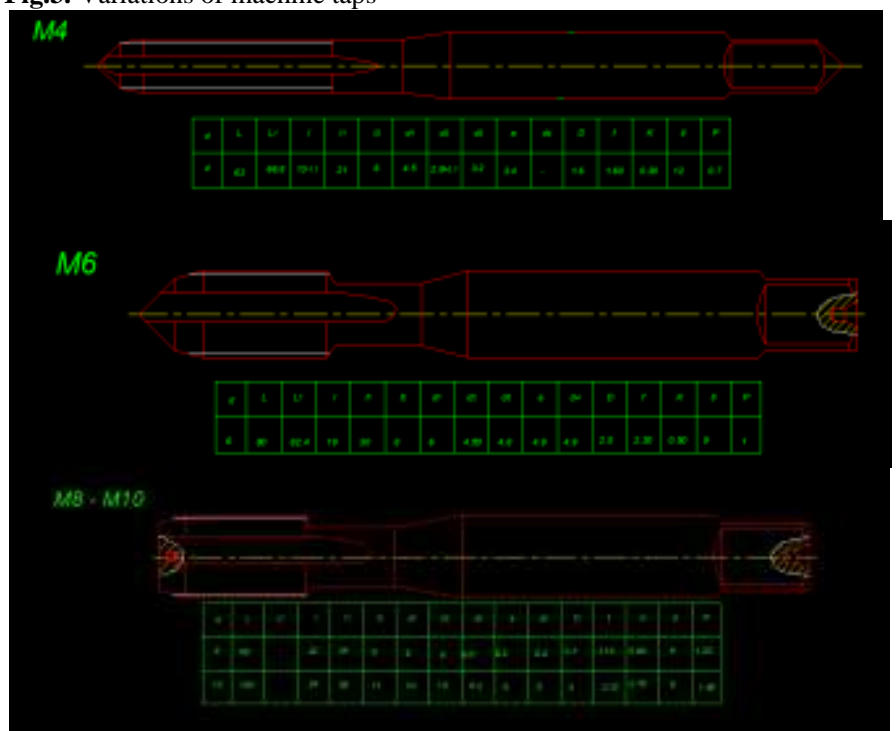

In table 1 are presented tolerances of all these incoming parameters which are object of this experimentation.

Table 1: Tolerances in dimensions of taps M4;M6; M8; M10

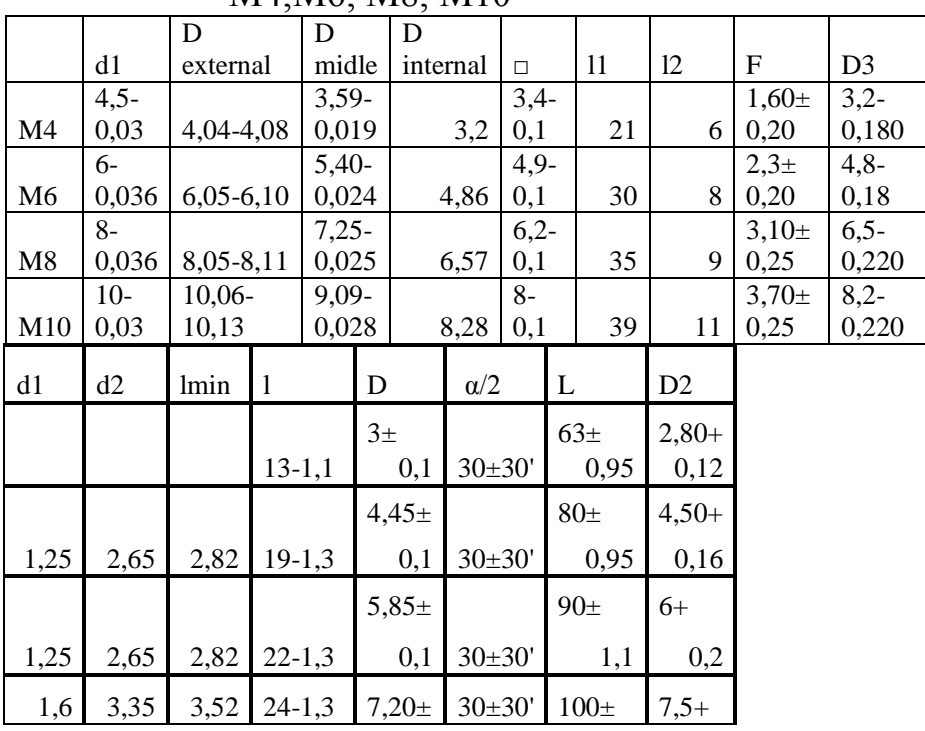

Definition of the problem: Planning the number of experimentation in order to exam tolerances in parameters of machine taps aiming to define the mistakes in producing taps and the factors influencing on the accuracy of taps.

\subsection{Definition of the method used}

The word ,experiment” comes from Latin word experimentum which means test or in another words scientific test with precision calculations and controlled environment. It is central thing in science.

Experiment in one of the most important purview of a science. Than the organize of 
Proc. of the Second Intl. Conf. on Advances in Mechanical and Automation Engineering - MAE 2015

Copyright ( $\odot$ Institute of Research Engineers and Doctors, USA .All rights reserved.

ISBN: 978-1-63248-045-3 doi: 10.15224/ 978-1-63248-045-3-130

experimental examination was worked tasks and choice program of the experiment. Efficiency of the experiment depends from the choice of measurements resources $[2,4]$.

There are some methods for planning experimentations. A model should be done. It could be linear, square /with 2 variables/ and volumetric. Mathematical modeling could be realized via some different methods (Monte Carlo, smallest squares etc.[3]). Most popular are regression methods.

Object of the experiment are taps for machines M4 M6 M8 M10. There are 2 pictures of taps' drawings with their dimensions which are the input parameters of the experiment.

The number of examined factors should be equal to the number of experimentations: L, de, dm, di, which means 4 experimentations.

In this article we present the experimentations in tables and drawings. Table 2 shows deviations of tolerances.

We choose only 4 parameters of all because they have most deviations: L, de, dm, di. On table 3 M4 is shown deviations of dimensions outside of allowable tolerance. We accept that 8 experimentations are enough.

Table 2: Mistakes (deviations from tolerances)

\begin{tabular}{|l|r|r|l|l|l|l|l|l|l|}
\hline & d1 & D e & D m & $\begin{array}{l}\text { i. } \\
\text { i. }\end{array}$ & 口 & I1 & I & F & D3 \\
\hline M4 & 4,4 & 4,02 & 3,57 & 3,3 & 3,1 & 20 & 15 & 1 & 2,9 \\
\hline M6 & 5,5 & 6 & 5,37 & 4,9 & 4,7 & 29 & 16 & 2,05 & 4,6 \\
\hline M8 & 8,55 & 8,01 & 7,22 & 6,6 & 6,3 & 34 & 24 & 3,4 & 6,2 \\
\hline M10 & 9,6 & 10,03 & 9,06 & 8,3 & 8,1 & 37 & 22 & 3,45 & 8,3 \\
\hline
\end{tabular}

\begin{tabular}{|r|r|r|r|r|r|r|}
\hline d1 & d2 & Imin & I2 & D & L & D2 \\
\hline & & & 5 & 2,8 & 61,5 & 2,6 \\
\hline 1 & 2,2 & 3 & 9 & 4,3 & 79 & 4,3 \\
\hline 2 & 2,1 & 2,5 & 7 & 5,7 & 92 & 5,78 \\
\hline 1 & 2,6 & 2,5 & 10 & 7,4 & 98 & 7,25 \\
\hline
\end{tabular}

Table 3: Tap M4

\begin{tabular}{|r|r|r|r|r|}
\hline M4 & D e, mm & D m, mm & D I, mm & L, mm \\
\hline 1 & 4,02 & 3,578 & 3,2 & 63,9 \\
\hline 2 & 4,08 & 3,586 & 3,162 & 63,7 \\
\hline 3 & 4,05 & 3,59 & 3,235 & 63,95 \\
\hline 4 & 4,06 & 3,574 & 3,184 & 63 \\
\hline 5 & 3,98 & 3,568 & 3,191 & 61,5 \\
\hline 6 & 4,08 & 3,575 & 3,283 & 63,5 \\
\hline 7 & 4,03 & 3,58 & 3,172 & 61,4 \\
\hline 8 & 4,04 & 3,585 & 3,163 & 63,1 \\
\hline
\end{tabular}

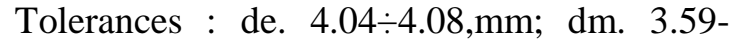

$0,019, \mathrm{~mm}$; di. 3,202 $\max , \mathrm{mm}$; L $63 \pm 0,95, \mathrm{~mm}$ (Figure 4).

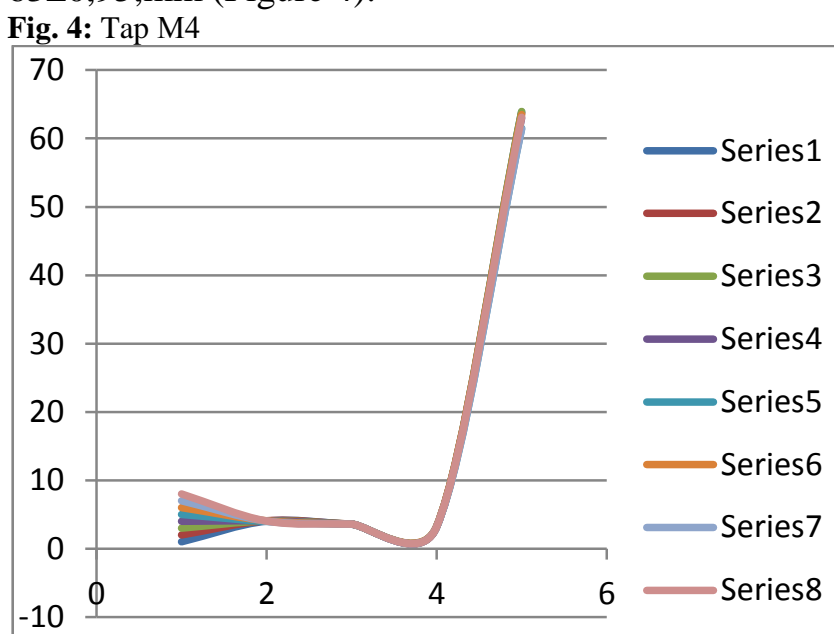

Table 4: Tap M6

\begin{tabular}{|r|r|r|r|r|}
\hline M6 & De.,mm & Dm.,mm & Di.,mm & L,mm \\
\hline 1 & 6,06 & 5,385 & 4,754 & 80,5 \\
\hline 2 & 6,03 & 5,39 & 4,801 & 78,8 \\
\hline 3 & 6,08 & 5,4 & 4,783 & 80,2 \\
\hline 4 & 6,07 & 5,405 & 4,704 & 79,6 \\
\hline 5 & 6,05 & 5,37 & 4,653 & 79,9 \\
\hline 6 & 6,08 & 5,39 & 4,781 & 80,2 \\
\hline 7 & 6,04 & 5,364 & 4,881 & 81,05 \\
\hline 8 & 6,1 & 5,405 & 4,952 & 80,7 \\
\hline
\end{tabular}

Tolerances: de. $6.05 \div 6.10$, mm; dm. 5.40$0,024, \mathrm{~mm}$; di. $4,868 \quad \max , \mathrm{mm} ; \quad \mathrm{L}$ $80 \pm 0,95, \mathrm{~mm}$ (Figure 5).

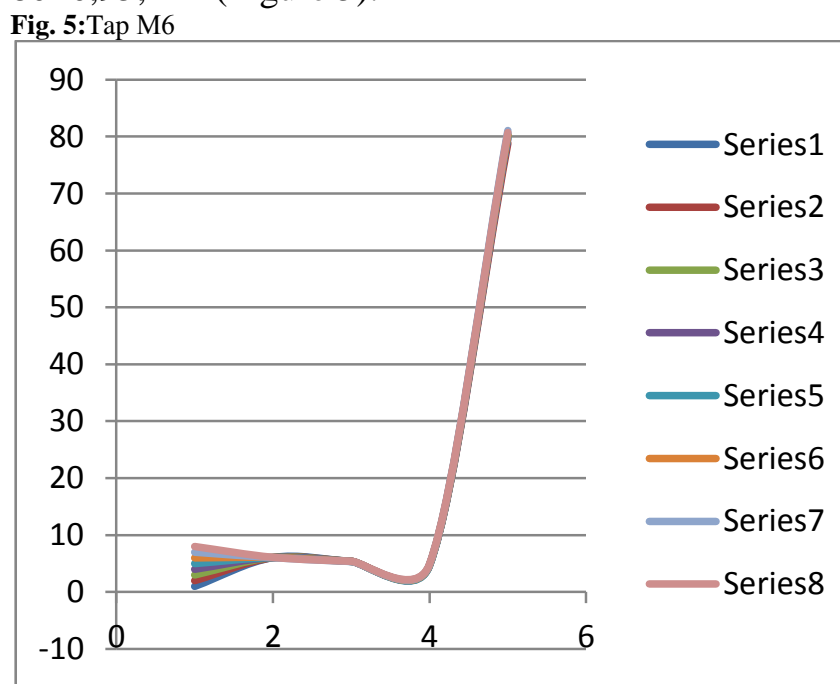


Proc. of the Second Intl. Conf. on Advances in Mechanical and Automation Engineering - MAE 2015

Copyright (C) Institute of Research Engineers and Doctors, USA .All rights reserved.

ISBN: 978-1-63248-045-3 doi: 10.15224/ 978-1-63248-045-3-130

Table 5: Tap M8

\begin{tabular}{|r|r|r|r|r|}
\hline M8 & De, $\mathrm{mm}$ & Dm, $\mathrm{mm}$ & $\mathrm{Di}, \mathrm{mm}$ & $\mathrm{L}, \mathrm{mm}$ \\
\hline 1 & 8,04 & 7,251 & 6,52 & 90 \\
\hline 2 & 8,03 & 7,24 & 6,473 & 88,5 \\
\hline 3 & 8,05 & 7,22 & 6,451 & 89,5 \\
\hline 4 & 8,08 & 7,21 & 6,425 & 89,4 \\
\hline 5 & 8,09 & 7,245 & 6,484 & 90,2 \\
\hline 6 & 8,1 & 7,251 & 6,533 & 90,2 \\
\hline 7 & 8,05 & 7,243 & 6,492 & 89,5 \\
\hline 8 & 8,02 & 7,226 & 6,431 & 91,5 \\
\hline
\end{tabular}

Tolerances: de. $8.05 \div 8.11, \mathrm{~mm}$; dm. 7.25-

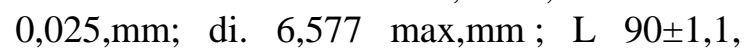
mm (Figure 6).

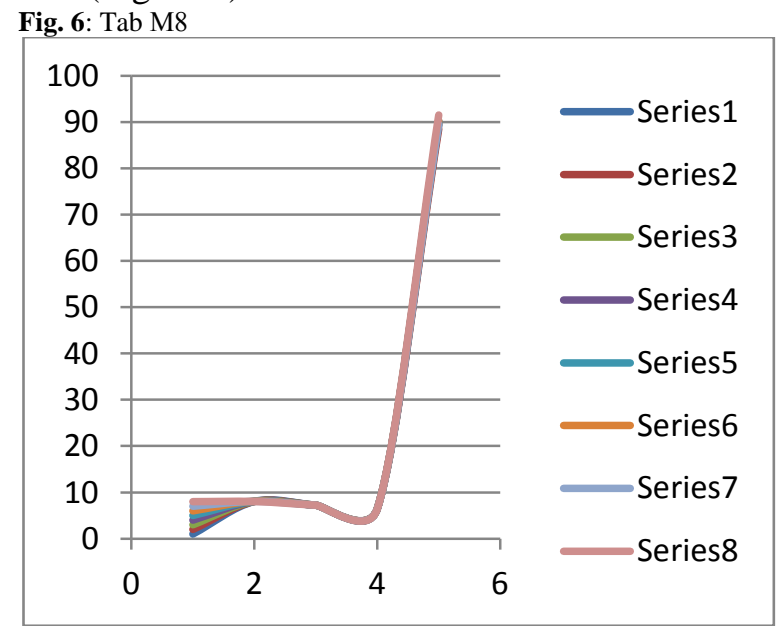

Table 6: Tap M10

\begin{tabular}{|c|c|c|c|c|}
\hline $\mathrm{M} 10$ & $\mathrm{De}, \mathrm{mm}$ & $\begin{array}{c}\mathrm{Dm}, \\
\mathrm{mm}\end{array}$ & $\mathrm{Di}, \mathrm{mm}$ & $\mathrm{L}, \mathrm{mm}$ \\
\hline 1 & 10,05 & 9,08 & 8,202 & 101,2 \\
\hline 2 & 10,07 & 9,09 & 8,253 & 100,4 \\
\hline 3 & 10,06 & 9,095 & 8,213 & 90,8 \\
\hline 4 & 10,06 & 9,075 & 8,181 & 90,5 \\
\hline 5 & 10,08 & 9,055 & 8,154 & 100,5 \\
\hline 6 & 10,1 & 9,06 & 8,172 & 100,4 \\
\hline 7 & 10,07 & 9,084 & 8,143 & 98,5 \\
\hline 8 & 10,09 & 9,09 & 8,147 & 90,9 \\
\hline
\end{tabular}

Tolerances: de. $10.06 \div 10.13, \mathrm{~mm} ; \mathrm{dm}$. 9,09-0,028,mm; di. 8,286 max, mm; L $100 \pm 1,1, \mathrm{~mm}$ (Figure 7 )
Fig. 7: Tab M10

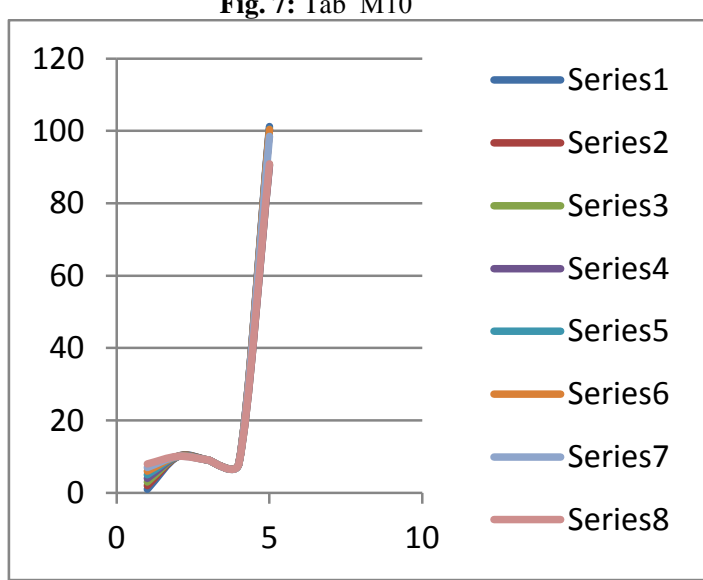

Analysis of technological mistakes in making thread - processing instruments is published in [1].

The multifactor analysis of mistakes in production of taps will be examined in another article

\section{CONCLUSION}

3.1 This article has presented portfolio analysis of GWG in the sector of activity. Table working drawing and working drawing of variation for production of 4 different kinds of taps has been presented. A table with tolerances is shown on the working dimensions.

3.2 The final of all types of taps and their purposes is presented. Four types of taps and their work drawings has been chosen. Eight experiments has been made of the four more often mistakes in measurements of deviations in taps dimensions. 8 experimentations for measurement of deviations from their dimensions have been made for the 4 most frequent mistakes. D1rowing of the experimentation has been presented. The dimensions of taps M4 M6 M8 M10 in the most of the cases are outside tolerances, which do not answer the standard DIN371 in production.

\section{REFERENCES:}

[1] Angelova D., S. Kartunov: Analysis of technological mistakes in making thread - processing instruments. In: Proceedings of the $23^{\text {th }}$ International Scientific And Technical Conference Automation of Discrete Production Engineering ADP, Sozopol - Jun 2014, ISSN - 1310 3946, pp. 237-243

[2] Dašić, P.: ARTICLE ,Klasifikacija naucnih disciplina I metodologija realizacije eksperimentalnih istrazivania,..Lecture of Summerschool. Kosovska Mitrovica, 2014

[3] Kisyov I.: Tehnika, Sofia, 1970; UDK 62+51(083)

[4] Petrov M.: Manuscript lecture, Gabrovo, TU, 2014 
Proc. of the Second Intl. Conf. on Advances in Mechanical and Automation Engineering - MAE 2015

Copyright $\odot$ Institute of Research Engineers and Doctors, USA .All rights reserved.

ISBN: 978-1-63248-045-3 doi: 10.15224/ 978-1-63248-045-3-130

\section{About the authors}

Prof. Dr-Ing. Stefan Kartunov, TU Gabrovo, Bulgaria, Hadji Dimitar Str. 4, Department MU, Mechanical Engineering, Lab. Micro- and Nanotechnologies

Research interests: Technological process of micro- and nano elements, CAD/CAM/CAE-studies, simulations and animations before/in the production

PhD Student Ing. Detelina Angelova, Technical University, Gabrovo, Bulgaria, Hadji Dimitar Str. 4, Department MU,

Mechanical Engineering, 